\title{
A Curious Case of Rectal Ejaculation
}

\author{
Frank L. Ventura ${ }^{1}$, Christopher M. Nguyen ${ }^{1}$, Alexander Dang ${ }^{1}$, Michelle Baliss ${ }^{1}$, Lindsay K. Sonstein ${ }^{1}$ \\ 1. Internal Medicine, University of Texas Medical Branch at Galveston, Galveston, USA
}

Corresponding author: Frank L. Ventura, flventur@utmb.edu

\begin{abstract}
Rectal-prostate fistulas are uncommon anatomical connections between the prostatic urethra and rectum that are typically iatrogenic but can also result from other underlying pathology. Here, we present a unique case of a rectal-prostate fistula causing the rectal passage of sperm.
\end{abstract}

\begin{abstract}
A 33-year-old male with a history of illicit drug use presented with five days of testicular pain and a substantial amount of sperm passage from his rectum with ejaculation for the past two years. Computed tomography and voiding cystourethrogram (VCUG) of the pelvis revealed evidence of a rectal-prostate fistula. He was treated with piperacillin-tazobactam, and a surgical fistula repair was performed. Further investigation divulged a three-week comatose state due to cocaine and phencyclidine intoxication two years prior with documentation suggesting a traumatic Foley catheter placement and strong suspicion for premature balloon dilation in the prostatic urethra. Repeat VCUG revealed resolution of the fistula with mildly reduced antegrade ejaculatory volume.
\end{abstract}

Cases secondary to Foley catheter placement have not been previously reported in the literature. Even though urethral catheters have been shown to be effective tools in healthcare, it is crucial for clinicians to recognize the numerous potential complications that oftentimes become an afterthought to many providers. This case not only highlights a rare complication of catheter use but also emphasizes the importance of provider mindfulness when utilizing seemingly benign therapies such as Foley catheters.

Categories: Internal Medicine, Urology, Gastroenterology

Keywords: rectourethral fistula, foley catheter, urology, internal medicine, fistulas

\section{Introduction}

Rectourethral fistulas (RUF) are uncommon pathologic communications between the rectum and lower urinary tract with an incidence of 0.5 per 100,000 per year [1]. The majority of adult cases are acquired, while most pediatric cases are due to congenital abnormalities [2-4]. Acquired RUFs occur due to surgery, radiation, trauma, and inflammatory states such as Crohn's disease [2]. Most cases are related to prostate cancer or caused by prostate cancer therapy [5]. Presenting symptoms typically manifest as pneumaturia, fecaluria, hematuria, and urinary tract infections [5,6]. Management of these fistulous connections is complex and typically requires surgical correction with varying surgical techniques depending on the underlying etiology and surgeon preference $[2,5]$. Here, we describe a case of RUF causing the rectal passage of sperm due to traumatic Foley catheter insertion.

Review began 08/08/2021 Review ended 08/16/2021 Published 08/20/2021

๑) Copyright 2021 Ventura et al. This is an open access article distributed under the terms of the Creative Commons Attribution License CC-BY 4.0., which permits unrestricted use, distribution, and reproduction in any medium, provided the original author and source are credited.
This article was previously presented as a meeting poster at the 2021 ACP National Abstract Competition in May 2021.

\section{Case Presentation}

A 33-year-old male with a history of illicit drug use presented with five days of testicular pain. He also noted a substantial amount of urine and sperm passage from his rectum in addition to pneumaturia and fecaluria for the past two years. Vital signs upon presentation were within normal limits. Physical examination was notable for left testicular swelling with a positive Prehn's sign and a defect in the anterior rectal wall on digital rectal examination. Labs showed a neutrophilic leukocytosis and urinalysis was suggestive of a urinary tract infection. Computed tomography (CT) of the pelvis revealed evidence of left epididymoorchitis and a gas-filled structure within the posterior aspect of the prostate communicating with the adjacent rectum, which was suggestive of a chronic appearing rectal-prostate fistula (Figure 1). Voiding cystourethrogram (VCUG) confirmed the presence of the fistula (Figure 2). 


\section{Cureus}

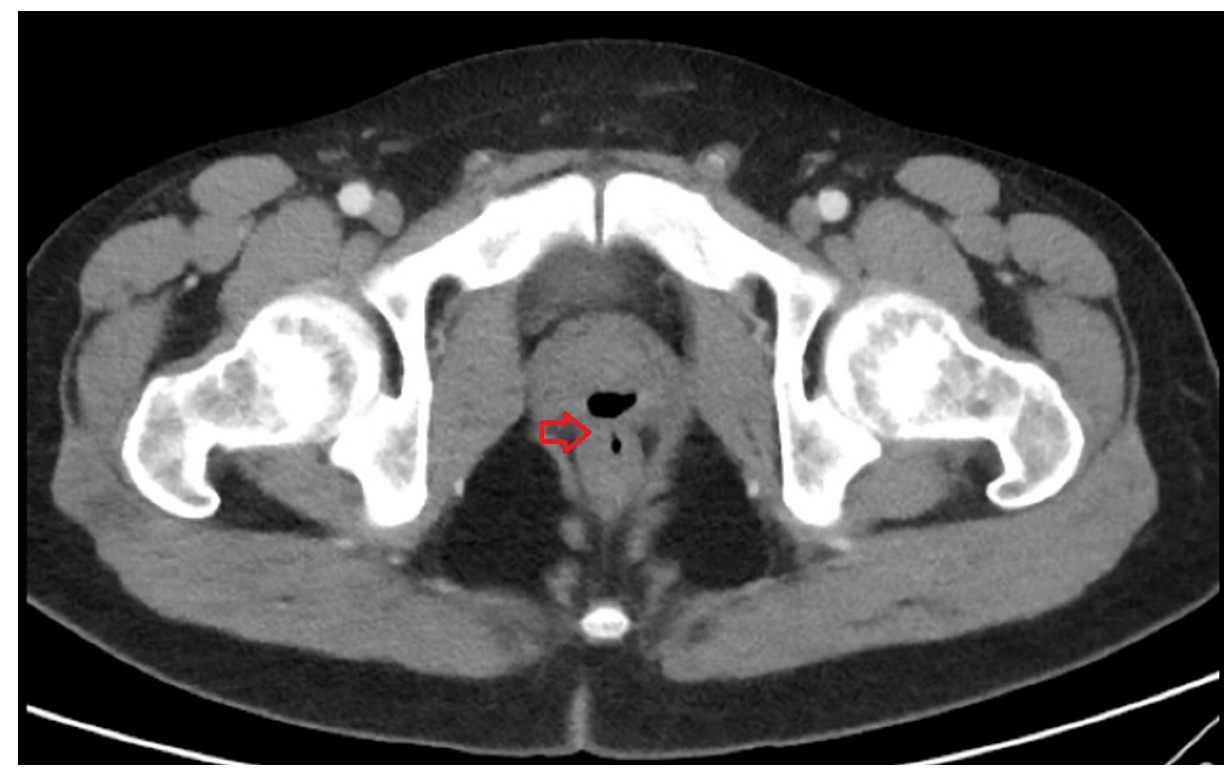

FIGURE 1: CT demonstrating gas-filled structure within the posterior aspect of the prostate communicating with the adjacent rectum.

CT: computed tomography

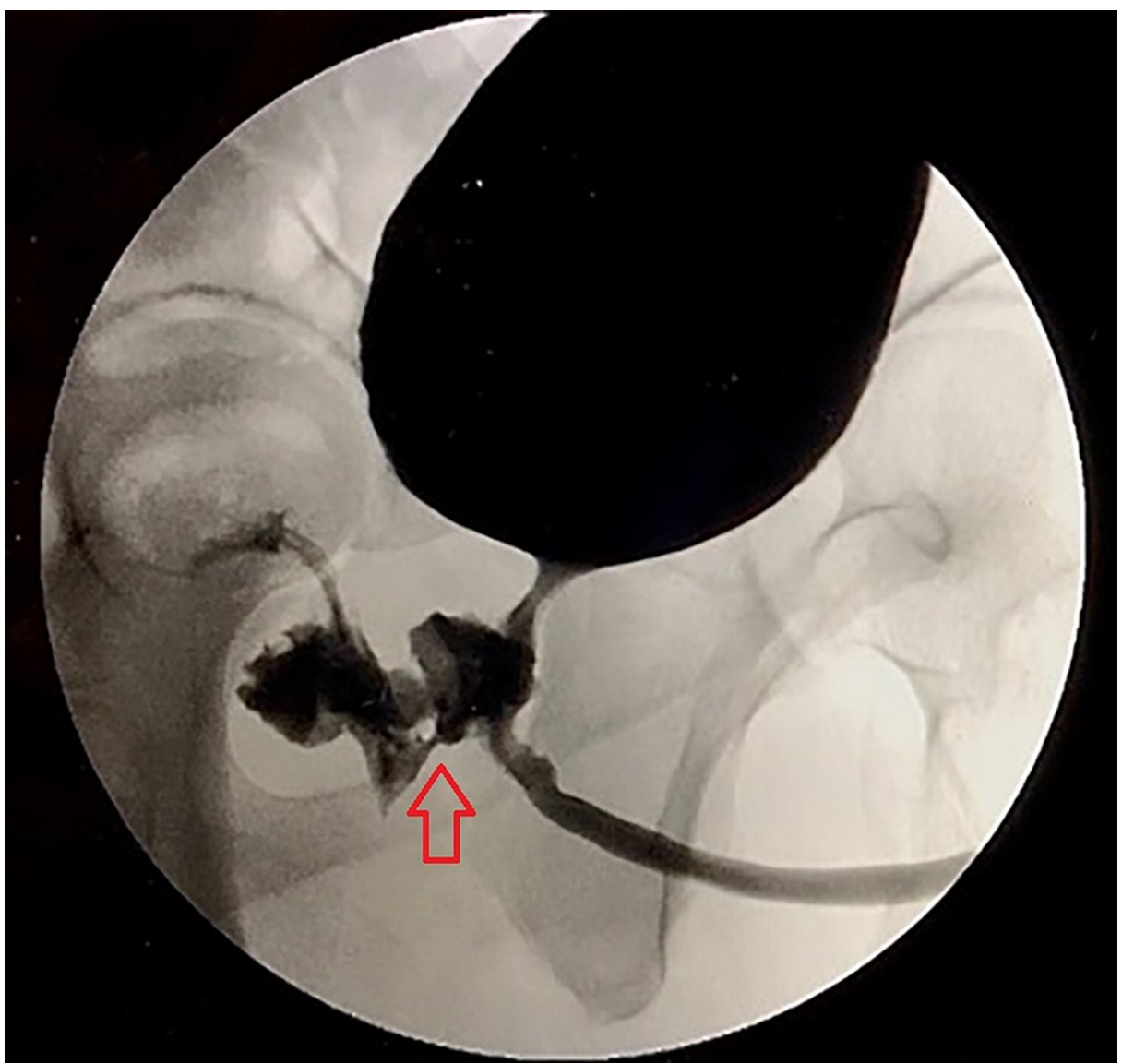

FIGURE 2: VCUG demonstrating evidence of fistulous communication of the urethra and rectum.

VCUG: voiding cystourethrogram 


\section{Cureus}

Extensive workup to rule out infectious causes including tuberculosis, inflammatory bowel disease, and malignancy was unremarkable. Additionally, the patient denied prior abdominal surgeries, rectal manipulation and penetration, or rectal trauma. Further investigation divulged a three-week comatose state due to cocaine and phencyclidine intoxication two years prior. Documentation suggested significant trauma with Foley catheter placement associated with hematuria during that hospitalization. The epididymoorchitis was treated with piperacillin-tazobactam. A joint colorectal and urologic surgical fistula repair was performed creating a rectal urethral advancement flap from the excised rectal wall with successful closure of the prostatic fistula. A suprapubic catheter was placed postclosure and subsequently removed after recovery. Repeat VCUG revealed resolution of the fistula and the patient recovered with only mildly reduced antegrade ejaculatory volume over several months (Figure 3).

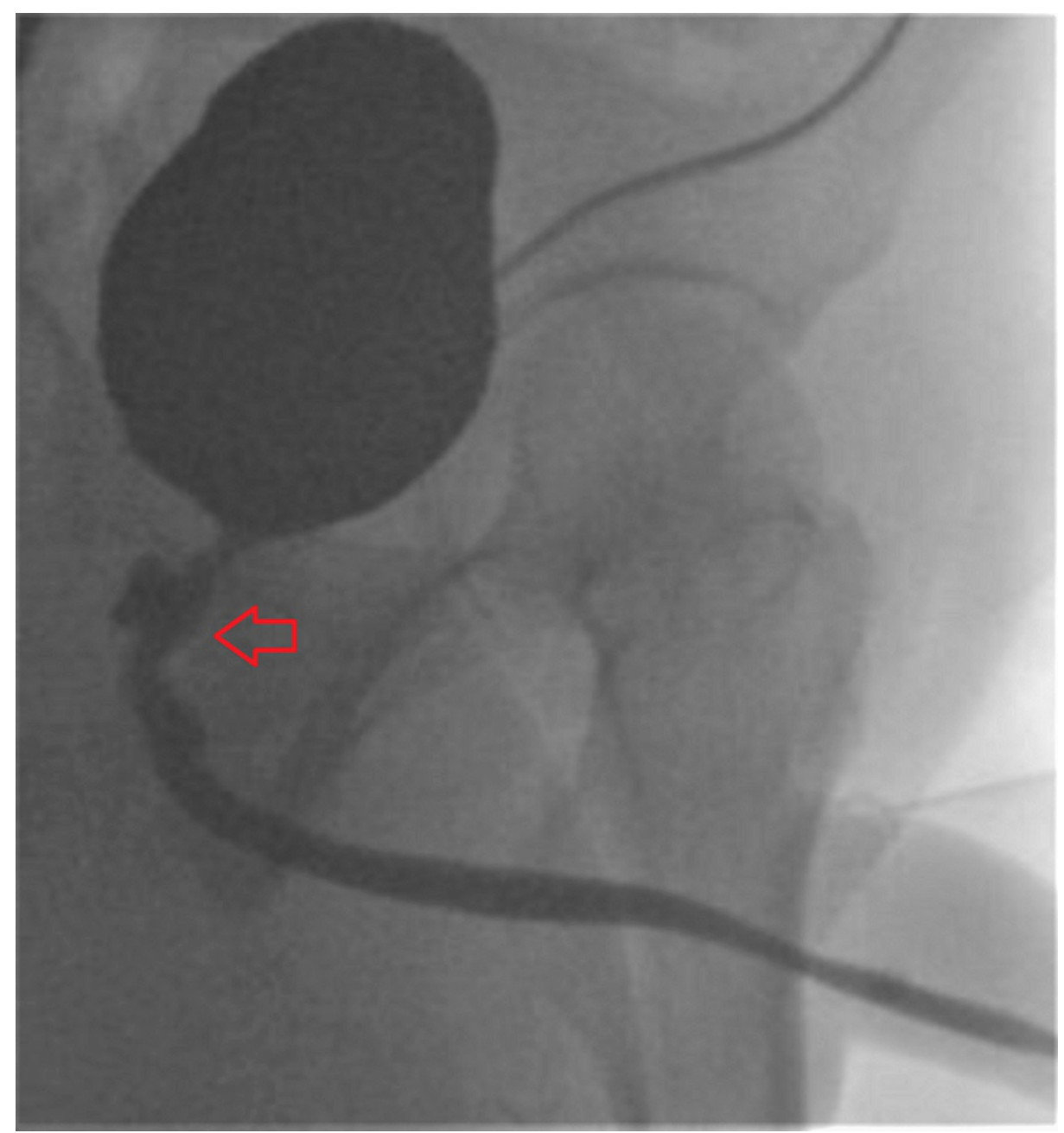

\section{FIGURE 3: VCUG demonstrating evidence of fistulous resolution of the} urethra and rectum.

VCUG: voiding cystourethrogram

\section{Discussion}

Several etiologies of acquired RUFs are well-established including prostate cancer with tumor invasion, rectal cancer, regional radiation, cryotherapy, surgery, diverticular disease, severe trauma, fistulizing Crohn's disease, and abscess rupture (Table 1 ) $[2,7,8]$. Cases caused by trauma typically occur following severe trauma with a large number of cases occurring during times of war [9]. Catheter-induced RUF is rare with limited reported cases. Few cases of intraperitoneal urinary bladder fistulas, urethrocutaneous fistulas, and colovesical fistulas associated with long-term indwelling catheter use have been reported in the literature [10-12]. Untreated cases result in recurrent urinary tract infections, pyelonephritis, and sepsis [6]. 


\section{Cureus}

\begin{tabular}{|c|c|c|c|c|c|c|c|c|c|c|c|}
\hline Investigators & Year & $\begin{array}{l}\text { Number of } \\
\text { patients }\end{array}$ & Age & Etiology & FU & UR & PU & HC & Surgery & SPC & Other \\
\hline Koh et al. [13] & 1997 & 1 & 73 & TURP & - & + & - & - & + & - & - \\
\hline Takaki et al. [14] & 1997 & 1 & 60 & $\mathrm{PCa}$ & - & + & - & - & + & - & - \\
\hline Goto et al. [15] & 2001 & 1 & 61 & $\mathrm{PCa}$ & - & - & - & - & - & - & + \\
\hline Kato et al. [16] & 2006 & 1 & 65 & $\mathrm{RP}$ & + & + & - & - & + & - & - \\
\hline Kumar et al. [17] & 2006 & 3 & $\sim 52$ & $\mathrm{P}$ & - & + & - & + & - & + & - \\
\hline Crippa et al. [18] & 2007 & 8 & $\sim 58$ & $\begin{array}{l}\text { RP (5/8), debride (1/8) TURP } \\
(2 / 8)\end{array}$ & + & - & + & - & + & - & - \\
\hline Chiu et al. [19] & 2008 & 1 & 70 & EBRT & + & + & + & - & - & + & - \\
\hline Khoder et al. [20] & 2009 & 1 & 71 & $\mathrm{RP}$ & - & - & - & - & - & - & + \\
\hline Takezawa et al. [21] & 2009 & 1 & 56 & RP & + & - & - & - & - & - & + \\
\hline $\begin{array}{l}\text { Samalavicius et al. } \\
\text { [22] }\end{array}$ & 2012 & 1 & 58 & BT & + & - & - & + & - & + & - \\
\hline Xing et al. [23] & 2016 & 1 & 75 & $\mathrm{P}$ & - & - & - & - & - & - & + \\
\hline Harris et al. [24] & 2017 & 201 & - & RP and ablation & + & - & - & - & + & - & - \\
\hline Ubrig et al. [25] & 2017 & 1 & 64 & TURP & - & + & - & - & - & - & + \\
\hline Moss et al. [26] & 2018 & 1 & 80 & BT & + & & + & - & & + & - \\
\hline Prabha et al. [27] & 2018 & 6 & $\sim 54$ & MVA (2/6), RP (4/6) & + & + & - & - & + & - & - \\
\hline Del Zingaro et al. [28] & 2020 & 1 & 75 & TURP & - & + & + & - & + & - & - \\
\hline Kuperus et al. [29] & 2020 & 1 & 70 & EBRT & - & + & - & - & + & - & - \\
\hline Pathak et al. [30] & 2020 & 1 & 70 & $P$ & - & + & - & - & + & - & - \\
\hline
\end{tabular}

\section{TABLE 1: Cases of rectourethral fistulas with etiology.}

BT: brachytherapy; EBRT: external beam radiation therapy; FU: fecaluria; HC: hematochezia; HIFU: high-intensity focused ultrasound; MVA: manual vacuum aspiration; P: prostatitis; PU: pneumaturia; RP: radical prostatectomy; SPC: suprapubic catheter; TURP: transurethral resection of the prostate; UR: urine leakage through rectum

Symptomatic urinary tract infections are seen in $80 \%$ of patients with colovesical fistulas while approximately $90 \%$ of patients experience pneumaturia and fecaluria [31]. Rectal passage of sperm is a rare symptom with few established cases involving fistulous rectal connections with the ejaculatory duct or seminal vesicles due to surgical treatment of malignancy or inflammatory bowel disease [32-34]. The presence of feces in the urine is considered to be a poor prognostic sign as this may be an indicator that the fistula may be large [35].

A definitive gold-standard modality of diagnosis is not well established even though many cases are diagnosed by clinical suspicion followed by direct visualization by rectoscopy or cystourethroscopy $[5,6]$. Other imaging modalities such as CT, magnetic resonance imaging, and cystourethrography have also been used; however, subsequent direct visualization of the fistula typically occurs [6].

Conservative resolution by urinary or fecal diversion is variable ranging from $14 \%$ to $54 \%$ [5]. Due to the overall effect on the quality of life, and because most cases require surgical intervention for definitive therapy, conservative management is generally reserved for patients who are poor surgical candidates or who prefer a trial of less invasive management $[5,34,36]$. More complex cases may require surgical repair and postsurgical urinary or fecal diversion to facilitate optimal healing, as was the case in our patient $[6,8]$. Several known poor prognostic factors exist including fistulas larger than $2 \mathrm{~cm}$ and a history of regional radiation or cryotherapy [6]. Various successful surgical approaches and techniques for RUF repair have been established. A recent retrospective review found no significant difference in fistula healing following transanal, transperineal, transabdominal, or York-Mason repair with an overall 91\% rate of successful repair [37]. Additionally, the study did not observe any difference in fistula healing in patients with or without urinary and/or fecal diversion [37]. Another study demonstrated multiple viable surgical approaches 
depending on the etiology, severity, and risk of recurrence [6].

This case not only highlights a rare complication of catheter use but also emphasizes the importance of provider mindfulness when utilizing seemingly benign therapies such as Foley catheters.

\section{Conclusions}

The importance of Foley catheters in healthcare is well-established. While it serves many uses in patient management, it is essential to stay wary of its complications as well. More frequent complications such as recurrent urinary tract infections and kidney and bladder damage have been reported in the literature; however, physicians should note other potential risks such as urethral injuries and RUFs. This case not only highlights a rare complication of catheter use but also emphasizes the importance of provider mindfulness when utilizing seemingly benign therapies such as Foley catheters.

\section{Additional Information}

\section{Disclosures}

Human subjects: Consent was obtained or waived by all participants in this study. Conflicts of interest: In compliance with the ICMJE uniform disclosure form, all authors declare the following: Payment/services info: All authors have declared that no financial support was received from any organization for the submitted work. Financial relationships: All authors have declared that they have no financial relationships at present or within the previous three years with any organizations that might have an interest in the submitted work. Other relationships: All authors have declared that there are no other relationships or activities that could appear to have influenced the submitted work.

\section{References}

1. Keller DS, Aboseif SR, Lesser T, Abbass MA, Tsay AT, Abbas MA: Algorithm-based multidisciplinary treatment approach for rectourethral fistula. Int J Colorectal Dis. 2015, 30:631-8. 10.1007/s00384-015-21830

2. Chen S, Gao R, Li H, Wang K: Management of acquired rectourethral fistulas in adults . Asian J Urol. 2018, 5:149-54. 10.1016/j.ajur.2018.01.003

3. Costa EC, Ferreira CT, Salle JL, Fraga JC: Diagnosis and management of congenital rectourethral fistula in a child with long tubular duplication of the colon and Klippel-Feil syndrome. J Pediatr Surg. 2011, 46:2184-6. 10.1016/j.jpedsurg.2011.08.022

4. Huang X, Tan SS, Chen Y, Li T: Acquired rectourethral and rectovaginal fistulas in children: a systematic review. Front Pediatr. 2021, 9:657251. 10.3389/fped.2021.657251

5. Cerdán Santacruz C, Cerdán Miguel J: Acquired recto-uretral fistulas: etiopathogenesis, diagnosis and therapeutic options. Cir Esp. 2015, 93:137-46. 10.1016/j.ciresp.2014.10.005

6. Choi JH, Jeon BG, Choi SG, et al.: Rectourethral fistula: systemic review of and experiences with various surgical treatment methods. Ann Coloproctol. 2014, 30:35-41. 10.3393/ac.2014.30.1.35

7. Hechenbleikner EM, Buckley JC, Wick EC: Acquired rectourethral fistulas in adults: a systematic review of surgical repair techniques and outcomes. Dis Colon Rectum. 2013, 56:374-83. 10.1097/DCR.0b013e318274dc87

8. Nyam DC, Pemberton JH: Management of iatrogenic rectourethral fistula. Dis Colon Rectum. 1999, 42:9947; discussion 997-9. 10.1007/BF02236689

9. Rajaian S, Rajadoss MP, Nayak S, Kekre NS: Traumatic rectourethral fistula repair: a potential application of porcine small intestinal submucosa. Indian J Urol. 2013, 29:148-50. 10.4103/0970-1591.114041

10. Hawary A, Clarke L, Taylor A, Duffy P: Enterovesical fistula: a rare complication of urethral catheterization . Adv Urol. 2009, 591204. 10.1155/2009/591204

11. Pindoria K, Reyad A, Youssef Y: Foley catheter through a colovesical fistula: an unusual method of diagnosis. BMJ Case Rep. 2014, 2014:bcr2014204968. 10.1136/bcr-2014-204968

12. Hong YK, Yu YD, Kang MH, Lee SR, Park DS, Oh JJ: A case of urethrocutaneous fistula: a forgotten segment of a broken urethral catheter. Urol Case Rep. 2014, 2:59-61. 10.1016/j.eucr.2014.01.002

13. Koh KB, Wightman JA, Tan KK: Successful closure of a recto-prostatic fistula . Med J Malaysia. 1997, 52:94-6.

14. Takaki R, Nishiyama T, Sekiya M, Ishizawa S, Junicho A, Fujishiro Y, Yabuzaki Y: Primary adenocarcinoma in the urethrorectal fistula. Int J Urol. 1997, 4:97-8. 10.1111/j.1442-2042.1997.tb00150.x

15. Goto T, Noguchi A, Hamamoto Y, et al.: [Primary squamous cell carcinoma of the prostate forming a rectourethral fistula: a case report]. Hinyokika Kiyo. 2001, 47:433-6.

16. Kato Y, Wakita T, Kanemitu Y, Hirabayashi A, Hayashi N: [Transanal repair of rectourethral fistula after radical retropubic prostatectomy: a case report]. Hinyokika Kiyo. 2006, 52:379-82.

17. Kumar S, Kekre NS, Gopalakrishnan G: Diagnosis and conservative treatment of tubercular rectoprostatic fistula. Ann R Coll Surg Engl. 2006, 88:26. 10.1308/147870806x83242

18. Crippa A, Dall'oglio MF, Nesrallah LJ, Hasegawa E, Antunes AA, Srougi M: The York-Mason technique for recto-urethral fistulas. Clinics (Sao Paulo). 2007, 62:699-704. 10.1590/s1807-59322007000600007

19. Chiu YC, Chang SC, Chen KK, Chang LS: Successful use of modified suprapubic catheter to rescue prostatorectal fistula. J Chin Med Assoc. 2008, 71:321-4. 10.1016/S1726-4901(08)70131-X

20. Khoder WY, Becker AJ, Schlenker B, Tritschler S, Bastian PJ, Stief CG: Conservative management of rectal perforation after nerve sparing endoscopic extraperitoneal radical prostatectomy (nsEERPE) in a patient with a past history of polypectomy. Eur J Med Res. 2009, 14:320-2. 10.1186/2047-783x-14-7-320

21. Takezawa K, Kakimoto K, Yoshida T, et al.: [Rectourethral fistula after radical retropubic prostatectomy: a case report]. Hinyokika Kiyo. 2009, 55:773-5. 
22. Samalavicius NE, Lunevicius R, Gupta RK, Poskus T, Ulys A: Gracilis muscle interposition with primary rectal without urethral repair for moderate sized rectourethral fistula caused by brachytherapy for prostate cancer: a case report. J Med Case Rep. 2012, 6:323. 10.1186/1752-1947-6-323

23. Xing L, Liu Z, Deng G, et al.: Xanthogranulomatous prostatitis with prostato-rectal fistula: a case report and review of the literature. Res Rep Urol. 2016, 8:165-8. 10.2147/RRU.S110658

24. Harris CR, McAninch JW, Mundy AR, et al.: Rectourethral fistulas secondary to prostate cancer treatment: management and outcomes from a multi-institutional combined experience. J Urol. 2017, 197:191-4. 10.1016/j.juro.2016.08.080

25. Ubrig B, Schmidt-Heikenfeld E, Degener S, Roosen A, Boy A: Minimally invasive repair of a prostatorectal fistula with an over-the-scope rectal clip. J Endourol Case Rep. 2017, 3:146-8. 10.1089/cren.2017.0097

26. Moss BF, Peracha AM: Rectal adenocarcinoma with rectoprostatic fistula following prostate brachytherapy . BMJ Case Rep. 2019, 12:e226151. 10.1136/bcr-2018-226151

27. Prabha V, Kadeli V: Repair of recto-urethral fistula with urethral augmentation by buccal mucosal graft and gracilis muscle flap interposition - our experience. Cent European J Urol. 2018, 71:121-8. 10.5173/ceju.2018.1353

28. Del Zingaro M, Cochetti G, Gaudio G, Tiezzi A, Paladini A, de Vermandois JA, Mearini E: Robotic conservative treatment for prostatourethrorectal fistula: original technique step by step. Int Braz J Urol. 2020, 46:481-2. 10.1590/S1677-5538.IBJU.2018.0584

29. Kuperus JM, Kim DG, Shah T, Ghareeb G, Lane BR: Rectourethral fistula following SpaceOAR gel placement for prostate cancer radiotherapy: a rare complication. Urol Case Rep. 2021, 35:101516. 10.1016/j.eucr.2020.101516

30. Pathak N, Keshavamurthy M, Rao K, Tabrez S, Ashwathaiya MB, Krishnappa P: A rare case of tubercular recto-prostatic urethral fistula with tuberculous orchitis. Urol Case Rep. 2020, 33:101355. 10.1016/j.eucr.2020.101355

31. Carson CC 3rd, Akwari OE: Rectal ejaculation and prostatic carcinoma. Urology. 1980, 16:188-9. 10.1016/0090-4295(80)90081-3

32. Hamidinia A: Recto-ejaculatory duct fistula: an unusual complication of Crohn's disease . J Urol. 1984, 131:123-4. 10.1016/s0022-5347(17)50233-5

33. Xia ZX, Cong JC, Zhang H: Rectoseminal vesicle fistula after radical surgery for rectal cancer: four case reports and a literature review. World J Clin Cases. 2020, 8:5645-56. 10.12998/wjcc.v8.i22.5645

34. Thomas C, Jones J, Jäger W, Hampel C, Thüroff JW, Gillitzer R: Incidence, clinical symptoms and management of rectourethral fistulas after radical prostatectomy. J Urol. 2010, 183:608-12. 10.1016/j.juro.2009.10.020

35. Kitazawa M, Hiraguri M, Maeda C, Yoshiki M, Horigome N, Kaneko G: Seminal vesicle-rectal fistula secondary to anastomotic leakage after low anterior resection for rectal cancer: a case report and brief literature review. Int Surg. 2014, 99:23-7. 10.9738/INTSURG-D-13-00164.1

36. Garcea G, Majid I, Sutton CD, Pattenden CJ, Thomas WM: Diagnosis and management of colovesical fistulae; six-year experience of 90 consecutive cases. Colorectal Dis. 2006, 8:347-52. 10.1111/j.14631318.2005.00928.x

37. Nfonsam VN, Mateka JJ, Prather AD, Marcet JE: Short-term outcomes of the surgical management of acquired rectourethral fistulas: does technique matter?. Res Rep Urol. 2013, 5:47-51. 10.2147/RRU.S28002 